\title{
Early Diagnosis of Renal Malfunction in Diabetics
}

\author{
Abnormal Proteinuria Revealed by Sodium Dodecyl Sulfate-Polyacrylamide Gel Electrophoresis \\ M. F. Lopes-Virella, G. Virella, G. Rosebrock, J. Sagel, J. Gonzalez, and J. Colwell \\ Department of Medicine, Endocrinology-Metabolism-Nutrition Division, Veterans Administration Medical Center, and Department \\ of Basic and Clinical Immunology and Microbiology, Medical University of South Carolina, Charleston, South Carolina, USA
}

\begin{abstract}
Summary. Renal damage is one of the most serious complications of diabetes mellitus. Most methods used to detect kidney malfunction show abnormalities only in the advanced stages. To find whether sodium dodecyl sulphate-polyacrylamide gel electrophoresis (SDS-PAGE) of the urinary proteins could give earlier indications of kidney malfunction, 68 patients with maturity-type diabetes and 22 with juvenile-type diabetes have been studied. Quantitative determination of proteinuria, urinary lysozyme, creatinine clearance and SDS-PAGE of urinary proteins were performed. Diabetics of both types with disease of more than 10 years duration showed significantly greater proteinuria and lysozymuria, higher serum creatinine values and lower creatinine clearances than their respective controls. Such differences were not seen in patients with diabetes of short duration. SDS-PAGE allowed detection of a higher proportion of patients with abnormalities. Thus, 3 out of 10 patients with juvenile diabetes of short duration showed predominant excretion of low molecular weight proteins, suggesting tubular dysfunction. This was not observed in the other groups of diabetics where increased elimination of high molecular weight proteins was noted, suggesting glomerular damage. SDS-PAGE revealed a higher frequency of abnormalities than other tests of renal function, with $67 \%$ abnormal in juvenile-type diabetes of greater than 10 years duration, $45 \%$ in maturity-type diabetes of less than 10 years duration and $76 \%$ abnormal in maturity-type diabetes of greater than 10 years duration.
\end{abstract}

Key words: Diabetes mellitus, proteinuria, nephropathy, SDS-PAGE.

It is estimated that death due to renal disease is 17 times more frequent in diabetics than in non-dia- betics [1], and that about $50 \%$ of all juvenile-type diabetics die as a result of renal disease [2,3]. When the diagnosis of renal disease is dependent on classical parameters, such as changes in creatinine clearance or detection of proteinuria in routine urinalysis, the finding of abnormalities closely precedes the onset of progressive renal failure [4], and little can be done to prevent this evolution. However, several authors have published data suggesting that through the use of more sophisticated and sensitive methods early changes in proteinuria can be detected at a stage where good metabolic control can result in a normalization of renal function [5-9]. According to most authors, the earlier changes in renal function result from increased glomerular filtration rate and glomerular permeability $[5,8,9]$, the latter resulting in increased albuminuria $[8,9]$. The existence of a tubular dysfunction has been investigated by the measurement of beta-2-microglobulin levels in the urine [7-9], and according to these investigations tubular proteinuria is not important in frequency or magnitude.

Recent progress in methodologies applicable to the study of proteinuria has allowed us to carry out a more thorough investigation of proteinuria in diabetic patients at different stages of evolution. Our method - colorimetric assay of total proteins, assay of lysozyme, and analytical study of urinary proteins by sodium dodecyl sulfate - polyacrylamide gel electrophoresis (SDS-PAGE) - besides being sensitive and discriminating, are sufficiently simple to be used routinely in diagnostic laboratories.

\section{Patients and Methods}

\section{Patients}

Ninety patients were included in this study and were randomly selected diabetic patients admitted for control of their diabetes to the Special Diagnostic and Therapeutic Unit at the Veterans' 
Administration Medical Center. Sixty-eight were maturity type diabetics ( 54 males, 15 females) with ages ranging from 29 to 70 years (mean age, 51). Forty-seven patients of this group had diabetes for less than 10 years, and 21 had diabetes for more than 10 years. Twenty-two were juvenile type diabetics (11 males, 11 females) with ages ranging from 21 to 56 years (mean age, 37). Most of these patients developed diabetes in early adulthood, and all were ketosis-prone, insulin-requiring diabetics. Ten had diabetes for less than 10 years and 12 had diabetes for more than 10 years. Eighteen healthy, nondiabetic individuals (13 males, 5 females) of ages ranging from 20 to 67 years (mean 44.7) were used as controls. There were no statistically significant differences between the group of controls and the different groups of diabetic patients with regard to age and sex distribution, with exception of the group of juvenile type diabetics with less than 10 years of duration. A subgroup of 8 controls, four males and four females, with ages ranging from 20 to 40 years (mean 31.2) was therefore segregated from the main group of controls and used for statistical comparison with this group of patients.

All controls were in good health and none was under treatment. All juvenile diabetics of less than 10 years duration were being treated with insulin (mean dosage, $39 \mathrm{UNPH}$ ). The juvenile diabetics with more than 10 yrs duration were primarily treated with insulin (mean dose $44 \mathrm{UNPH}$ ) but three patients had additional therapy (lipid lowering drugs in one, anti-hypertensive drugs in two). Of the 47 patients with maturity type diabetes of less than 10 years duration 29 were treated with insulin (mean dosage $39 \mathrm{U}$ $\mathrm{NPH}), 11$ were treated with oral hypoglycemic agents and diet, and 8 with diet alone. Seventeen patients in this group were under some form of associated therapy, mainly lipid-lowering agents, cardiac glycosides, anti-hypertensive agents, and vasodilating agents. Of the 21 patients with maturity type diabetes of more than 10 years duration, 17 were treated with insulin (mean doage $55 \mathrm{U}$ $\mathrm{NPH}$ ) and 4 with a combination of diet and oral hypoglycemic agents. Eight patients in this last group were under associated therapy with drugs of the same type as used in the group of maturity type diabetics of less than 10 years duration.

Informed consent was obtained for all patients and controls included in this study.

\section{Patient Evaluation}

Retinopathy, peripheral neuropathy, and hypertension were evaluated in all patients included in the study by a careful routine physical, ophthalmologic and neurologic examination. Questionable abnormalities were further evaluated by ophthalmologic consultation and nerve conduction studies.

Patients with blood pressure consistently greater than 140 / $90 \mathrm{~mm} \mathrm{Hg}$ or patients with documentation of previous hypertension requiring treatment were considered hypertensive. No special attention was given to the degree of metabolic control at the time of urine collection.

\section{Urine Collection and Preparation}

A $24 \mathrm{~h}$ urine specimen was collected from all patients and controls. After noting the total volume, a small aliquot of unconcentrated urine was kept for lysozyme assay and for total protein assay. A larger sample (100 to $200 \mathrm{ml}$ ) was concentrated by negativepressure ultrafiltration [10], and was used for SDS-PAGE and, occasionally, for determination of total proteins.

\section{Determination of Total Urinary Proteins}

Two colorimetric methods were employed. For concentrated urine samples we used the biuret method, with a minimal detection limit of $5 \mathrm{mg} / \mathrm{ml}$. Most total proteins in urine, however, were determined using the Bio-Rad protein assay, with which it is possible to assay concentrations up to $0.1 \mathrm{mg} / \mathrm{ml}$ accurately.

\section{Lysozyme Determination}

Lysozyme was determined by the lysoplate method [11], using lysozyme standards purchased from Kallestad Laboratories, Inc. (Chaska, Minn. 55318). When unconcentrated urine was used for the assay, this enzyme was not detectable in normal controls. The lower limit of detection for this method, in our laboratory, is $1-2 \mu \mathrm{g} / \mathrm{ml}$.

\section{$S D S-P A G E$}

The methodology employed was as previously described [10]. Each gel was loaded with a $100-\mu l$ sample of concentrated urine, previously assayed for protein concentration and adjusted by dilution to contain $200 \mu \mathrm{g}$ of protein. Two controls were used: (a) a mixture of proteins of known molecular weight, including IgM, IgG, transferrin, human serum albumin, egg albumin, chymotrypsinogen, and lysozyme, and (b) a sample of a normal human serum, both diluted not to exceed a load of $200 \mu \mathrm{g}$ of protein in their respective gels. The interpretation of results was based on the visual inspection of the gels after separation and staining of the separated proteins. Normal urines showed very few fractions, including primarily albumin and some faint bands of higher and lower molecular weight. In some urines from normal individuals, a distinct band of molecular weight between transferrin and IgG was also seen. The abnormal SDS-PAGE patterns were subdivided into several categories. When there was an increase in the elimination of proteins of high molecular weight, particularly albumin and transferrin, the proteinuria was considered glomerular $(\mathrm{G})$. We also considered as glomerular proteinuria cases where the only change was a marked increase in albuminuria. If, in addition to the high-molecular-weight proteins the urine showed traces of lowmolecular-weight proteins, this was considered as mixed proteinuria, predominantly glomerular $[\mathrm{M}(\mathrm{G})]$. Mixed proteinuria was subdivided into two more subtypes: true mixed $(M)$, when the proportions of high- and low-molecular-weight proteins were roughly equivalent; and mixed, predominantly tubular [M(T)], when low molecular weight proteins distinctly predominate. Finally, if the separation showed only relatively low amounts of albumin and large amounts of low-molecular-weight proteins, the proteinuria was considered tubular $(\mathrm{T})$. The classification of the proteinuria for any given patient was based on the blind interpretation of the separation in SDS-PAGE by two different observers.

\section{Serum and Urine Creatinine Determinations}

Serum and urine creatinine were determined by a semi-automated method based on the hydroxide picrate reaction [12]. All creatinine clearance tests were corrected to 1.73 sq meters body surface area.

\section{Results}

A summary of the results of the determinations of total urinary proteins, lysozymuria, serum creatinine and creatinine clearance, and the results of the analytical study of urinary proteins by SDS-PAGE are given in table I, together with the results of statistical 


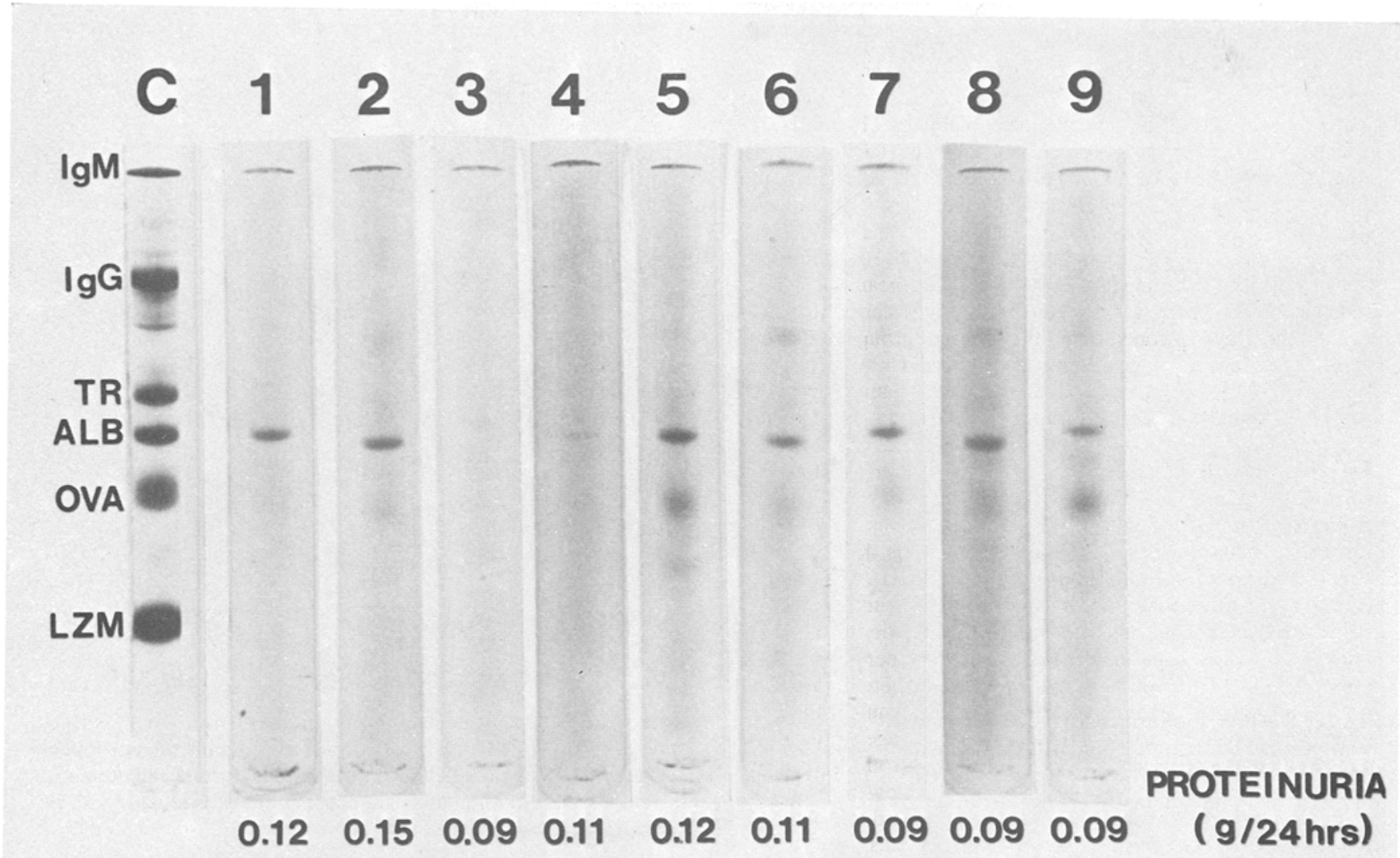

Fig. 1. SDS-PAGE of urines from normal donors. Gel $\mathrm{c}$ was used to separate reference proteins of known molecular weight: IgM, IgG, transferrin (TR), serum albumin (ALB), egg albumin (OVA), and lysozyme (LZM). The figures below each gel indicate the 24-hour proteinuria values

comparisons between all the quantitative parameters in normal controls and in the four groups of diabetic patients. This table shows that patients with less than 10 years duration of their diabetes do not present significantly abnormal quantitative data, with the exception of the increased creatinine clearances detectable in juvenile-type diabetics with less than 10 years duration. In contrast, patients with long-standing disease show significantly abnormal proteinuria, lysozymuria, serum creatinine, and creatinine clearances. In normal individuals albumin is the predominant urinary protein with no evidence of increased amounts of proteins of higher or lower molecular weight (Fig. 1), SDS-PAGE showed a high frequency of abnormal proteinuria in all groups of diabetic patients, even in cases where all other parameters were normal (Table 1 and Fig. 2).

The higher sensitivity of SDS-PAGE as a screening method for evidence of renal malfunction is better appreciated if we compare the frequencies of abnormal values for proteinuria, lysozymuria, and creatinine clearance and the frequency of abnormal proteinuria, as seen by SDS-PAGE (Fig. 3). In this comparison we considered the following as abnormal: (1) proteinuria exceeding the mean +2 standard deviations (SD) of the proteinuria in the corresponding group of normal controls (2) the detection of quantitable amounts of lysozyme; (3) creatinine clearance below the mean $-2 \mathrm{SD}$ of the corresponding group of normal controls.

In the group of 10 juvenile type diabetics with less than 10 years of evolution (Fig. 3), only two patients had increased total proteinuria, only two had detectable lysozyme and all had normal creatinine clearances while 3 had abnormal SDS-PAGE. Abnormal SDS-PAGE and lysozymuria were found in one patient, while 2 others with abnormal SDSPAGE had undetectable lysozyme, and the second patient with traces of urinary lysozyme had normal SDS-PAGE. In the group of 12 juvenile type diabetics with more than 10 years duration, the frequency of abnormalities was considerably higher 


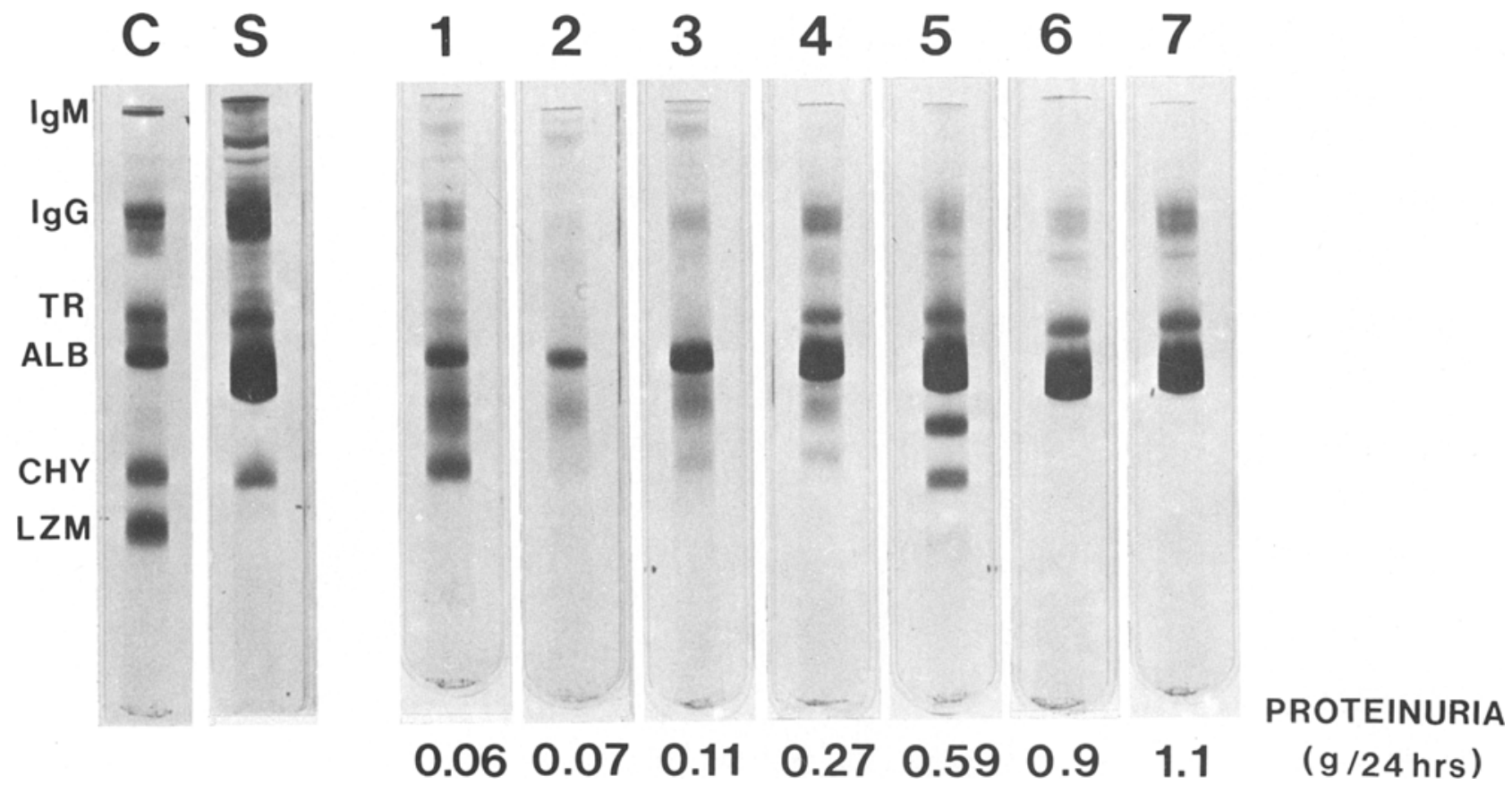

Fig. 2. SDS-PAGE of urines from diabetic patients. Gel $\mathrm{C}$ was used to separate reference proteins of known molecular weight: IgM, IgG, transferrin (TR), serum albumin (ALB), chymotrypsinogen (CHY), and lysozyme (LZM). Gel S was used to separate normal human serum. The values for 24-hour proteinuria are indicated below gels 1-7. Proteinuria was classified as normal in gel 2; glomerular in gels 6 and 7; mixed predominantly glomerular in gels 4 and 5 ; mixed in gel 3; and mixed, predominantly tubular in gel 1
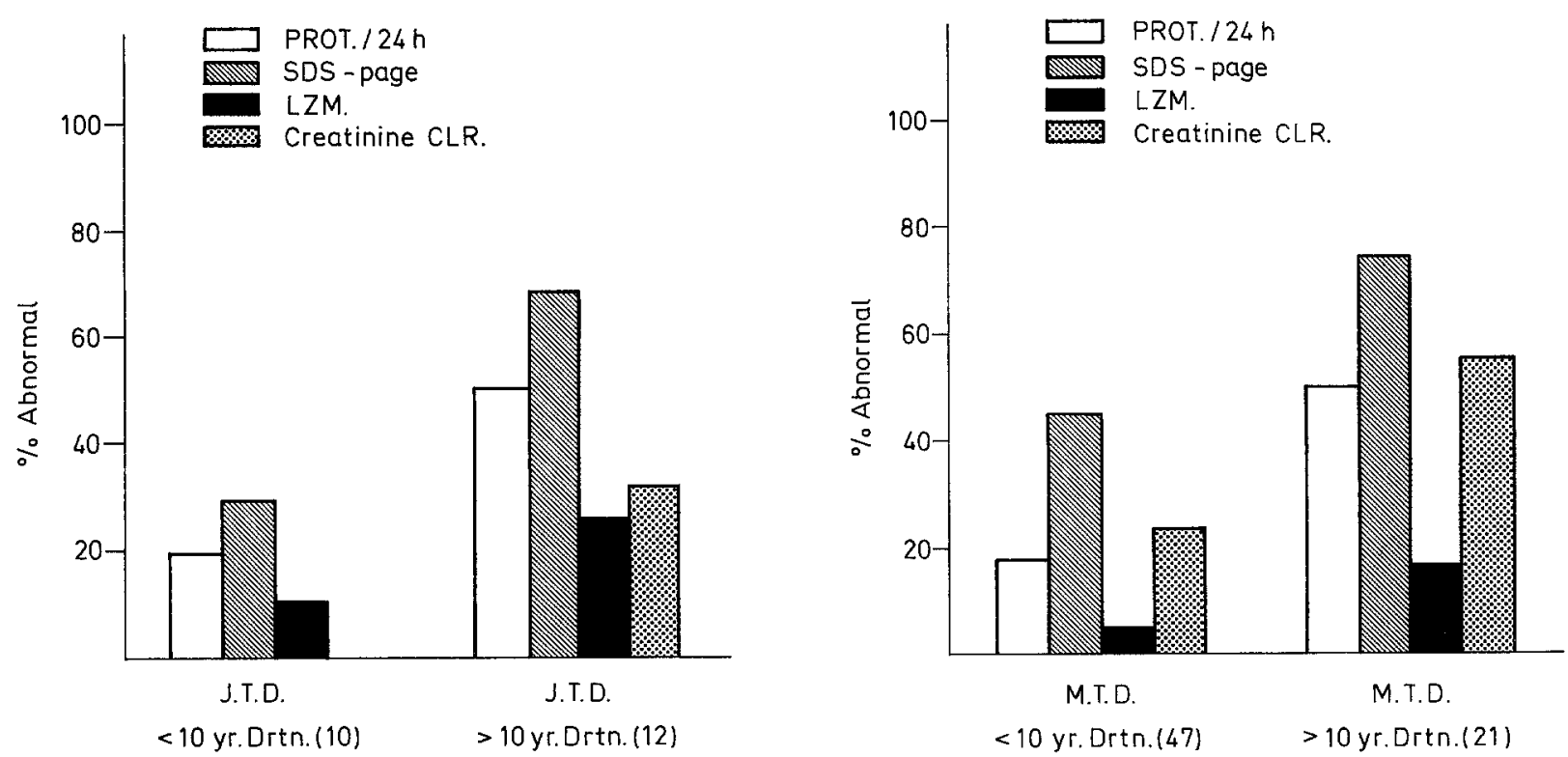

Fig. 3. Graphic representation of the percentage of abnormal findings in the four groups of diabetic patients included in this study: Juvenile-type diabetics (JTD) with duration shorter or longer than 10 years, maturity-type diabetics (MTD) with duration shorter or longer than 10 years. Numbers of subjects in each group are shown in parentheses.

PROT. $/ 24 \mathrm{hr}=24 \mathrm{~h}$ proteinuria; SDS-PAGE = sodium dodecyl sulphate-polyacrylamide gel electrophoresis; LZM = urinary lysozyme; Creatinine CLR $=$ creatinine clearance 
Table 1. Determinations of total proteinuria, lysozymuria, serum creatinine, creatinine clearance and separation of urinary proteins by SDS-PAGE

\begin{tabular}{|c|c|c|c|c|c|c|c|}
\hline \multirow[t]{2}{*}{ Group } & \multirow[t]{2}{*}{ No. } & \multirow{2}{*}{$\begin{array}{l}\text { Proteinuria } \\
(\mathrm{mg} / 24 \mathrm{~h})\end{array}$} & \multirow{2}{*}{$\begin{array}{l}\text { Lysozymuria } \\
(\mu \mathrm{g} / \mathrm{ml})\end{array}$} & \multirow{2}{*}{$\begin{array}{l}\text { Serum } \\
\text { creatinine } \\
(\mathrm{mg} / \mathrm{dl})\end{array}$} & \multirow{2}{*}{$\begin{array}{l}\text { Creatinine } \\
\text { clearance } \\
\text { (ml/min) }\end{array}$} & \multicolumn{2}{|c|}{ SDS-PAGE } \\
\hline & & & & & & $\overline{\mathrm{N}}$ & A $(\%)$ \\
\hline Normals (A) & 18 & $92 \pm 38$ & n.d. & $0.85 \pm 0.18$ & $102 \pm 9.2$ & 18 & $0(0)$ \\
\hline Normals (B) & 8 & $74 \pm 32$ & n.d. & $0.8 \pm 0.15$ & $110 \pm 5.8$ & 8 & $0(0)$ \\
\hline $\begin{array}{l}\text { Juvenile-type diabetes } \\
<10 \text { years }\end{array}$ & 10 & $87 \pm 48^{a}$ & $0.082 \pm 0.26^{\mathrm{a}}$ & $0.77 \pm 0.24^{a}$ & $131 \pm 20^{b}$ & 7 & $3(10)$ \\
\hline $\begin{array}{l}\text { Juvenile-type diabetes } \\
>10 \text { years }\end{array}$ & 12 & $886 \pm 1782^{b}$ & $0.63 \pm 1.35^{b}$ & $1.23 \pm 0.74^{\mathrm{b}}$ & $80 \pm 29^{c}$ & 4 & $8(66)$ \\
\hline $\begin{array}{l}\text { Maturity-type diabetes } \\
<10 \text { years }\end{array}$ & 47 & $126 \pm 110^{\mathrm{a}}$ & $0.025 \pm 0.12^{\mathrm{a}}$ & $0.88 \pm 1.9^{a}$ & $108 \pm 27^{a}$ & 26 & $21(45)$ \\
\hline $\begin{array}{l}\text { Maturity-type diabetes } \\
>10 \text { years }\end{array}$ & 21 & $474 \pm 737^{b}$ & $0.65 \pm 1.63^{b}$ & $1.34 \pm 0.62^{b}$ & $71 \pm 27^{\mathrm{d}}$ & 5 & $16(76)$ \\
\hline
\end{tabular}

Normals $(\mathrm{A})=$ total group of normals

Normals (B) = sub-group of normals, age and sex matched with Juvenile-type diabetes of less than 10 yrs. duration

a Statistical comparison with corresponding group of normals showed no significant differences

b Statistical comparison with corresponding group of normals showed a significant difference $(p<0.05)$

c Statistical comparison with corresponding group of normals showed a significant difference $(\mathrm{p}<0.01)$

d Statistical comparison with corresponding group of normals showed a significant difference $(\mathrm{p}<0.001)$

$\mathrm{N}=$ Normal; $\mathrm{A}=$ Abnormal; $\mathrm{n}$. $\mathrm{d}$. $=$ non-detectable

(Fig. 3). SDS-PAGE revealed again a higher frequency of abnormalities; 8 patients had abnormal profiles $(67 \%)$. In this group most patients with abnormal SDS-PAGE had increased proteinuria, but only 3 had abnormal creatinine clearances. Lysozymuria was found in 3 patients, one of whom had normal SDS-PAGE.

The frequency of abnormalities among 47 patients with maturity type diabetes of less than 10 years duration was slightly higher than that observed in juvenile type diabetics with similar lenght of disease (Fig. 3). Twenty-one patients had abnormal SDS-PAGE, while total proteinuria was only mildly elevated (up to $320 \mathrm{mg} / 24 \mathrm{hr}$ ) in 8 patients. Lysozymuria was detected in 2 patients, one of whom had normal SDS-PAGE. The creatinine clearance was slightly low in 10 patients $(64$ to $81 \mathrm{ml} / \mathrm{min}$ in patients of ages ranging between 41 and 63 years).

The maximal frequency of changes was found among patients with maturity type diabetes of more than 10 years duration (Fig. 3). Of the 21 patients included in this group, 16 had abnormal SDS-PAGE, 5 of which had excretion of total proteins in the normal range. Lysozyme was detected in 4 patients, all showing other abnormal parameters. Creatinine clearances were abnormal in 9 patients, one of whom, with a clearance of $71 \mathrm{ml} / \mathrm{min}$, had a normal SDS-PAGE, and four had normal $24 \mathrm{hr}$ proteinuria.

A detailed analysis of the relationships between creatinine clearance, proteinuria, and the results of urine separation on SDS-PAGE is shown in Table 2.
Table 2. Frequencies of abnormal proteinuria, defined both quantitatively and qualitatively, in diabetics with or without renal insufficiency, as determined by creatinine clearances

\begin{tabular}{|c|c|c|c|c|c|}
\hline \multirow[t]{2}{*}{ Group } & \multirow{2}{*}{$\begin{array}{l}\text { Creatinine } \\
\text { Clearance }\end{array}$} & \multicolumn{2}{|c|}{ Proteinuria } & \multicolumn{2}{|c|}{ SDS-PAGE } \\
\hline & & $\mathrm{N}^{\mathrm{b}}$ & $\bar{A}$ & $\overline{\mathrm{N}}$ & $\mathrm{A}$ \\
\hline Juvenile-type & $>98^{a}$ & $8^{b}$ & 2 & 7 & 3 \\
\hline diabetes $<10$ years & $<98$ & - & - & - & - \\
\hline Juvenile-type & $>84^{a}$ & 1 & 4 & 1 & 4 \\
\hline diabetes $>10$ years & $<84$ & 1 & 2 & 0 & 3 \\
\hline Maturity-type & $>84^{\mathrm{a}}$ & 25 & 6 & 16 & 15 \\
\hline diabetes $<10$ years & $<84$ & 8 & 2 & 5 & 5 \\
\hline Maturity-type & $>84^{a}$ & 3 & 4 & 1 & 6 \\
\hline diabetes $>10$ years & $<84$ & 4 & 5 & 1 & 8 \\
\hline
\end{tabular}

a Mean -2 standard deviations (SD) for the corresponding control group

b Normal values were defined as those not exceeding the mean value $+2 \mathrm{SD}$ of the corresponding control group

$\mathrm{N}=$ Normal; $\mathrm{A}=$ Abnormal

This table shows that the frequency of abnormal proteinuria, both quantitatively and qualitatively, is almost identical in patients with or without evidence of renal insufficiency, as judged by creatinine clearance, with a higher sensitivity in detection of abnormalities in the case of SDS-PAGE.

The detailed analysis of the results of SDS-PAGE in our patients is summarized in Table 3. Of interest is the prevalence of mixed and mixed-tubular proteinuria among the small group of juvenile type diabetics of short duration. On the other hand, 
Table 3. Results of SDS-PAGE in diabetic patients

\begin{tabular}{lrrllll}
\hline & $\mathrm{N}$ & $\mathrm{G}$ & $\mathrm{M}(\mathrm{G})$ & $\mathrm{M}$ & $\mathrm{M}(\mathrm{T})$ & $\mathrm{T}$ \\
\hline Juvenile-type diabetes <10 years & $7(70 \%)$ & 0 & 0 & $1(10 \%)$ & $1(10 \%)$ & $1(10 \%)$ \\
Juvenile-type diabetes $>10$ years & $4(33 \%)$ & $4(33 \%)$ & $4(33 \%)$ & 0 & 0 & 0 \\
Maturity-type diabetes <10 years & $26(55 \%)$ & $10(21 \%)$ & $6(13 \%)$ & $5(11 \%)$ & 0 & 0 \\
Maturity-type diabetes $>10$ years & $5(24 \%)$ & $7(33 \%)$ & $5(24 \%)$ & $1(5 \%)$ & $3(14 \%)$ & 0 \\
\hline
\end{tabular}

$\mathrm{N}=$ Normal electrophoretic pattern; $\mathrm{G}=$ Glomerular proteinuria; $\mathrm{M}(\mathrm{G})=$ Mixed proteinuria, predominantly glomerular; $\mathrm{M}=\mathrm{Mixed}$ proteinuria; $\mathrm{M}(\mathrm{T})=$ Mixed proteinuria, predominantly tubular; $\mathrm{T}=$ Tubular proteinuria

Table 4. Hypertension in diabetic patients

\begin{tabular}{llll}
\hline Patients & $\begin{array}{l}\text { Number of } \\
\text { cases }\end{array}$ & Hypertension & $\begin{array}{l}\text { Hypertension with } \\
\text { proteinuria and/or } \\
\text { abnormal SDS-PAGE }\end{array}$ \\
\hline Juvenile-type diabetes <10 years duration & 10 & 0 & 0 \\
Juvenile-type diabetes $>10$ years duration & 12 & 2 & 1 \\
Maturity-type diabetes <10 years duration & 47 & 2 & 1 \\
Maturity-type diabetes $>10$ years duration & 21 & 5 & 5 \\
\hline
\end{tabular}

Table 5. Frequency of microvascular complications and abnormal proteinuria in diabetic patients

\begin{tabular}{|c|c|c|c|c|c|c|}
\hline 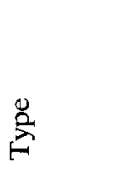 & 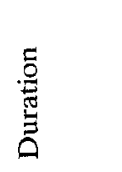 & 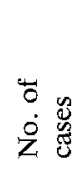 & 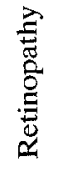 & 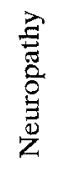 & 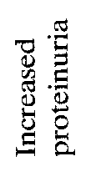 & 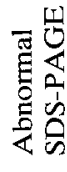 \\
\hline Juvenile & $\begin{array}{l}<10 \mathrm{yr} . \\
>10 \mathrm{yr} .\end{array}$ & $\begin{array}{l}10 \\
12\end{array}$ & $\begin{array}{l}0 \\
10^{\mathrm{a}}\end{array}$ & $\begin{array}{l}1 \\
8\end{array}$ & $\begin{array}{l}1 \\
6\end{array}$ & $\begin{array}{l}3 \\
8\end{array}$ \\
\hline Maturity & $\begin{array}{l}<10 \mathrm{yr} . \\
>10 \mathrm{yr} .\end{array}$ & $\begin{array}{l}47 \\
21\end{array}$ & $\begin{array}{l}2^{\mathrm{b}} \\
11^{\mathrm{c}}\end{array}$ & $\begin{array}{l}10 \\
13\end{array}$ & $\begin{array}{r}9 \\
12\end{array}$ & $\begin{array}{l}21 \\
16\end{array}$ \\
\hline
\end{tabular}

a 6 cases with background retinopathy and 4 with proliferative lesions

b Background retinopathy

c 8 cases with background retinopathy and 3 with proliferative retinopathy

glomerular and mixed, predominantly glomerular proteinuria appear with considerable frequency in the groups of patients with long duration and also predominate in the group of maturity type diabetics of short duration.

To evaluate the possible relationships between hypertension and proteinuria as seen by SDS-PAGE [15], all patients were screened for hypertension. As shown in Table 4, only a small proportion of our patients showed hypertension. The highest frequency was found among adult type diabetics of long duration. All five patients in this last group had proteinuria and abnormal SDS-PAGE, and 3 of them had abnormal creatinine clearances.

A comparison of the results of SDS-PAGE, total proteinuria determination and clinical detection of retinopathy and neuropathy is shown in Table 5. This table suggests that SDS-PAGE detects abnormal proteinuria in diabetics of short duration, even in the absence of clinical evidence of microvascular disease. At later stages, however, the finding of abnormal SDS-PAGE patterns tended to correlate with other clinical and laboratorial evidence of microvascular disease.

\section{Discussion}

SDS-PAGE was introduced as a method for the rapid screening of tubular proteinuria by Waldmann et al. [17], and also as a method to differentiate between glomerular and tubular proteinuria by Pesce et al. [18]. More recently, SDS-PAGE has been applied to larger groups of patients, and in comparison with other methods of the screening for renal damage, the remarkable sensitivity of the method became apparent $[15,19,20]$. This sensitivity permits detection of abnormalities when all other indices of renal function are within normal limits.

In diabetic patients early screening of renal malfunction is particularly important. Some early studies pointed toward SDS-PAGE as a technique with great potential in this respect. Mulli et al. [19], in a study of three diabetic patients with normal kidney function by classical parameters, reported tubular proteinuria in all. Boesken et al. [15] claimed that in their experience two-thirds of their patients with glomerular proteinuria had normal total urinary protein content. The present study documents this capacity of SDSPAGE to detect abnormalities when other tests of 
kidney function are normal. The advantage of SDSPAGE over creatinine clearance, total $24 \mathrm{~h}$ proteinuria, or lysozyme determinations, is mainly apparent in patients with diabetes of short duration. In such patients, many show mixed proteinuria or even predominantly tubular proteinuria, particularly among the group of juvenile-type diabetics. The excretion of low-molecular-weight proteins reflects impaired tubular reabsorption, which could be a functional alteration or a very early manifestation of renal diabetic microangiopathy, affecting predominantly tubular function. In either case, it will be necessary to follow longitudinally the evolution of proteinuria in patients showing early changes, attempting to correlate the observed changes with therapeutic control and general metabolic parameters.

Acknowledgement. We wish to acknowledge Mr. Shelton Ellis, Mrs. Grace Liu and Ms. Gracie Evans for technical assistance; Ms. Mary D. Adams for the photography work, and Mr. Charles Smith for excellent editorial assistance.

\section{References}

1. Entmacher, P.S., Root, H. F., Marks, H. H.: Longevity in diabetic patients in recent years. Diabetes 13, 373-377 (1964)

2. Knowles, H. C., Jr.: Magnitude of the renal failure problem in diabetic patients. Kidney Int. 6 (Suppl. 1), 2-7 (1974)

3. Balodimos, M. C.: Diabetic nephropathy. In: Joslin's Diabetes Mellitus. Marble, A., White, P., Bradley, R. F., Krall, L.P. (eds.), 11th Ed., pp. 526-561. Philadelphia: Lea \& Febiger 1971

4. Goldstein, H. H.: Discussion: The problem of end-stage nephropathy. Kidney Int. 6 (Suppl. 1), 21-26 (1974)

5. Ditzel, J., Junker, K.: Abnormal glomerular filtration rate, renal plasma flow, and renal protein excretion in early and long-term juvenile diabetics. Br. Med. J. 1972 II, 13-19

6. Morgensen, D.E. L.: Urinary albumin excretion in early and long-term juvenile diabetes. Scand. J. Clin. Lab. Invest. 28 183-193 (1971)

7. Morgensen, D. E.: Renal function changes in diabetes. Diabetes $\mathbf{2 5}, 872-879$ (1976)
8. Parving, H. H., Noer, I., Deckert, T., Errin, P. E., Nielsen, S. L., Lyngøe, T., Morgensen, D. E., Rørth, M., Svendsen, R. A., Trap-Jensen, T., Lassen, N. A.: The effect of metabolic regulation on microvascular permeability to small and large molecules in short-term juvenile diabetics. Diabetologia 12, 161-166 (1976)

9. Parving, H. H.: Increased microvascular permeability to plasma proteins in short- and long-term juvenile diabetics. Diabetes 25, 884-889 (1976)

10. Pires, M. T., da Cunha, A. S., Virella, F., Simoes, J.: Analytical characterization of urinary proteins by sodium dodecyl sulfate polyacrylamide gel electrophoresis in renal disease. Nephron 14, 361-372 (1975)

11. Osserman, E. F., Lawlor, D. P.: Serum and urinary lysozyme (muramidase) in monocytic and monomyelocytic leukemia. $\mathbf{J}$. Exp. Med. 124, 921-951 (1966)

12. Hawk, P. B., Oser, B. L., Summerson, W. T. (Eds.): Practical Physiological Chemistry, 12th ed., pp. 506. New York: Blakinston-McGraw-Hill 1947

13. Boesken, W. A., Schneider, G., Reuscher, A.: Early detection of diabetic microangiopathy by the glomerular pattern of urinary proteins (Abstract). Diabetologia 12, 381 (1976)

14. Waldman, T. A., Strober, W., Mogielnicki, R. P.: The renal handling of low molecular weight proteins. II. Disorders of serum protein catabolism in patients with tubular proteinuria, the nephrotic syndrome or uremia. J. Clin. Invest. 51, 2162-2174 (1972)

15. Pesce, A. T., Boreisha, I., Pollack, V. E.: Rapid differentiation of glomerular and tubular proteinuria by sodium dodecyl sulfate polyacrylamide gel electrophoresis. Clin. Chim. Acta 40, 27-34 (1972)

16. Mulli, J. C., Balant, L., Giromini, M., Fabre, T.: Analysis of proteinuria in health and disease using sodium dodecyl sulfateacrylamide gel electrophoresis. Eur. J. Clin. Invest. 4, 253-259 (1974)

17. Boesken, W. H., Kopf, K., Schollmeyer, P.: Differentiation of proteinuric diseases by disc electrophoretic molecular weight analysis of urinary proteins. Clin. Nephrol. 1, 311-318 (1973)

Received: June 1, 1978

and in revised form: November 13, 1978

Dr. M. F. Lopes-Virella

Department of Medicine

Endocrinology-Metabolism-Nutrition Division

Medical University of South Carolina

171 Ashley Avenue

Charleston, SC 29403

USA 